\title{
SABERES RELACIONADOS AO AUTOCUIDADO ENTRE MULHERES DA ÁREA RURAL DO SUL DO BRASIL
}

\author{
M oara Ailane THU M a, T eila CE OLIN ${ }^{b}$, A nelise M iritz BORG ES ${ }^{c}$, Rita M aria HECK ${ }^{d}$
}

\section{RESUM 0}

Este estudo teve por objetivo conhecer as ações de autocuidado de um grupo de mulheres rurais do município de Pelotas, R io G rande do Sul. T ratou-se de uma pesquisa qualitativa, com 11 mulheres, residentes na área rural do município. A coleta de dados ocorreu entre maio e junho de 2010, através de entrevista semiestruturada. Foi realizada a anál ise de conteúdo por temas. A s informantes mais antigas participam do grupo na comunidade há 12 anos, realizando trabal hos manuais e trocas de saberes sobre 0 uso das plantas medicinais. 0 autocuidado faz parte das ações dessas mulheres, o qual é executado das mais diversas formas, abrangendo o contexto familiar, a transmissão de crenças e dos hábitos através das gerações. Espera-se, contribuir para a valorização da mulher rural, conscientizando os profissionais de saúde, quanto à realização de práticas em saúde que atendam as reais necessidades da comunidade assistida, resgatando a cultura relacionada ao cuidar-se.

D escritores: A utocuidado. Saúde da mulher. População rural. Plantas medicinais. Cuidados de enfer magem.

\section{RESUMEN}

E ste estudio tuvo como objetivo conocer las acciones de autocuidado de un grupo de mujer es rurales del munici pio de $P$ elotas, $\mathrm{R}$ io $\mathrm{G}$ rande do Sul, B rasil. Setrata de una investigación cualitativa, con 11 mujeres residentes en el área rural del munici pio. $L$ a recolección de datos ocur rió entre mayo y junio de 2010 a través de entrevista semiestructurada. Se realizó el análisis de contenido para los temas. L as participantes más antiguas participan del grupo en la comunidad hace 12 años, haciendo artesanías y el intercambio de conocimientos sobre el uso de plantas medicinales. E I autocuidado es parte de las acciones de estas mujeres, que se ejecuta en muchas formas diferentes, incluyendo el contexto familiar, la transmisión de las creencias y de los hábitos a través de generaciones. Seespera contribuir a la valoración dela mujer rural, a la concienciación de profesionales de la salud, en lo referido a la realización de prácticas de salud que satisfagan las necesidades reales de la comunidad asistida, rescatando la cultura relacionada con el autocuidado.

D escriptores: Autocuidado. Salud de la mujer. Población rural. P lantas medicinales. A tención de enfermería. T ítulo: Conocimientos relacionados a el autocuidado de mujeres del área rural del Sur de Brasil.

\section{ABST RACT}

This articleaimed to study self-careactions by a group of rural women from the city of P elotas, state of Rio G randedo Sul, $B$ razil. T his was a qualitative research in which 11 women living in the city's rural area have participated. D ata collection occur red betw een M ay and J une, 2010, through semi-structured interviews. A content analysis was per formed on the data. The oldest informants have partici pated in the community group for 12 years, doing w orkmanship and exchanging know ledge on the use of medicinal plants. Self-care is part of the actions of these women, which are performed in many different ways, including actions in the family context, and the transmission of beli efs and habits through generations. We hopeto contribute to the valorization of rural women, educating health professionals on health practices that meet real needs of the assisted community, reclaiming the culture related to self-care.

Descriptors: Self care. Women's health. Rural population. Plants, medicinal. N ursing care. $T$ itle: Knowledges related to self-care in health among women of Southern B razil's rural area.

\footnotetext{
a Enfermeira graduada pela Faculdade de Enfermagem (FEn) da U niversidade Federal de Pelotas (UF Pel), Pelotas, Rio Grande do Sul, Brasil.

${ }^{b}$ M estre em Enfermagem, Professora A ssistente da FEn/ U F Pel, Pelotas, Rio G rande do Sul, Brasil.

'M estre em E nfermagem, D outoranda pelo Programa de Pós-G raduação em E nfermagem da U niversidade Federal do Rio G rande (FU RG ),

Rio Grande, Rio Grande do Sul, Brasil.

d D outora em Enfermagem, Professora A djunta da FEn/ U F Pel, Pelotas, Rio Grande do Sul, Brasil.
} 


\section{INT RODUÇÃO}

A agricultura familiar no Brasil é fonte de recursos para as famílias com menor renda, além de fator redutor do êxodo rural, o que precisa ser considerado, dado o significativo crescimento urbano $^{(1)}$. Na década de 40 , em torno de $31,3 \%$, da população residia nas cidades, enquanto no ano de 2000 já eram 81,2\%(2). No R io G rande do Sul (RS), em 2010 a população distribuía-se em 51,33\% no sexo feminino e $48,67 \%$ no sexo masculino, sendo que apenas $14,90 \%$ residem no meio rural (2).

$\mathrm{N}$ a cidade de Pelotas, local onde foi realizada a pesquisa, em 2010 a população total foi estimada em 327.778 mil habitantes, sendo que destes, apenas $22.082(6,74 \%)$ eram habitantes da área rural. Os dados também revelam que Pelotas é o terceiro município do RS que apresenta o maior número de moradores na zona rural ${ }^{(2)}$.

E $m$ relação à divisão do trabalho por sexo, na agricultura, as mulheres em geral ocupam uma posição subordinada e seu trabalho geralmente aparece como ajuda, mesmo quando elas trabalham tanto quanto os homens ou executam as mesmas atividades que el es ${ }^{(3)}$. Sabe-se também que o trabaIho da mulher é considerado por muitas pessoas, improdutivo, tendo em vista que abrange o campo dos cuidados com a família, alimentação, saúde, educação e higiene. Estas tarefas, consider adas domésticas e por vezes, não valorizadas economicamente pela sociedade, são executadas na maioria das vezes concomitantemente com as tarefas fora do lar.

Entretanto, a vida da mulher atual, em diversos lugares, tem passado por relevantes mudanças, seja no espaço político, social, cultural e principalmente no econômico, as quais foram observadas a partir do momento em que a mulher deixou de ser a "dona do lar" e passou a buscar seu espaço no mercado de trabalho. D esde então, muitas foram suas conquistas, como o direito de votar e a licença maternidade, 0 acesso às escolas e universidades, a ocupação de cargos de chefia, dentre outras. T ais transformações interferiram diretamente em seu cotidiano, pois além do papel de mãe e dona de casa, a mulher passou a trabalhar fora do seu lar, aumentando assim, os fatores de risco para desenvolver diver sas doenças crônicas.

Conforme a Organização Pan-A mericana de Saúde (OPAS), os fatores de risco estão relacionados aos níveis de estresse e controle, ocupação e atividades diárias, fatores genéticos, estilo de vida, hábitos de saúde e alimentar, além das alterações ambientais, interferem na vida das pessoas ${ }^{(4)}$.

N esse processo, em 2004 o M inistério da Saúde implementou a Política $\mathrm{N}$ acional de A tenção Integral à Saúde da M ulher, que baseia-se em promover a melhoria das condições de vida e saúde das mulheres brasileiras, mediante a garantia de direitos legal mente constituídos e a ampliação do acesso aos meios e serviços de promoção, prevenção, assistência e recuper ação da saúde em todo 0 território brasileiro(5).

A Política Nacional de Promoção de Saúde também foi umas das ações implementadas com vistas à melhoria da qualidade de vida dos usuários, bem como dos serviços prestados pelo Sis-tema Ú nico de Saúde (SUS) $)^{(6)}$. A partir disso, evidenciase a necessidade de valorizar a saúde no meio rural, considerando as diferentes condições de vida, trabalho e saúde da população, incluindo a própria capacidade/ vontade da pessoa realizar o autocuidado. Para tal, busca-se aliar estas ações às políticas nacionais que amparam esse enfoque na saúde e o trabal ho executado pelos profissionais.

Assim, compreende-se 0 autocuidado como à capacidade que os indivíduos têm de cuidar de si, desempenhando atividades em seu próprio benefício, a fim de manter a vida, a saúde e o bem-estar próprio(7). Compete aos enfermeiros, realizarem 0 estímulo para que os indivíduos desenvolvam o autocuidado, partindo do princípio de que 0 ato de cuidar exige um olhar para a dimensão total do ser, valorizando o conhecimento das realidades e expectativas da população atendida.

Acredita-se que a realização deste estudo viabilizará reflexões quanto ao processo de saúdee doença delineado pelas mulheres rurais e as maneiras que realizam 0 autocuidado em saúde. $N$ este contexto, 0 objetivo desta pesquisa foi conhecer as ações de autocuidado de um grupo de mulheres rurais do município de Pelotas/RS.

\section{METODOLOGIA}

T rata-se de uma pesquisa qual itativa do tipo exploratória e descritiva ${ }^{(8)}$, realizada em um distrito rural do município de Pelotas/RS, com um grupo composto por 11 mulheres, as quais realizavam seus encontros mensais em um salão da igreja católica local. Estes encontros visam a trocas de ideias em relação aos trabal hos artesanais, assim como sobre o uso das plantas medicinais na saúde. 
A realização da pesquisa com esse público alvo foi sugerida pela coordenadora do grupo de pesquisa "Plantas bioativas de uso humano por famílias de agricultores de base ecológica na região Sul do RS", da Faculdade de Enfermagem da U niversidade F ederal de Pelotas (U F Pel), a qual conhecia algumas integrantes do grupo interiorano, assim como os interesses das pesquisadoras em trabaIhar com mulheres. A inserção das pesquisadoras se deu de maneira gradativa após a obtenção do aceite pelas mulheres, permitindo uma maior aproximação as integrantes do grupo a cada encontro. Os sujeitos foram selecionados a partir dos seguintes critérios: ser moradora e trabalhadora da área rural; participar do grupo abordado; ter idade superior a 18 anos e comunicar-se em língua portuguesa.

Foi garantido o sigilo e 0 anonimato de acordo a Resolução 196/ 96 do Conselho N acional de Saúde ${ }^{(9)}$. A identificação das mulheres pesquisadas foi realizada através da letra $M$ seguida pela numeração indicando a ordem de realização das entrevistas. 0 projeto foi aprovado pelo Comitê de Ética e Pesquisa da Faculdade de Enfermagem da UFPel (protocolo no 103/ 2010).

Os dados foram coletados em maio e junho de 2010. N estes encontros estavam presentes 14 mulheres, das quais 11 fizeram parte do estudo de acordo com os critérios de participação. Para a coleta de dados foi utilizada a entrevista semiestruturada ${ }^{(8)}$ gravada, a qual foi direcionada às maneiras de realização do autocuidado em saúde pelas mulheres.

Os dados obtidos foram transcritos, preservando sua integridade; posterior mente classificados e agrupados em diferentes temas(8), a fim de qualificar a análise ${ }^{(10)}$ das informações coletadas. A pós sucessivas leituras, os dados foram organizados em três temas: contextualização dos sujeitos do estudo, autocuidado em saúde realizado pelas agricultoras e o papel dos profissionais no autocuidado em saúde. Esses foram confrontados com as refer ências consultadas juntamente com a reflexão e experiência das autoras.

\section{RESULTADOS E DISCUSSÃO DOS DADOS}

\section{Contextualização dos sujeitos do estudo}

F oram entrevistadas 11 mulheres com idades entre 19 e 68 anos, ocorrendo prevalência de mulhe- res casadas, vinculadas a religião católica. Quanto à descendência étnica, referiram ser de origem alemã, italiana, pomerana e com miscigenação entre africanos, índios e europeus, quando se referiram à brasileira. Em relação ao número de filhos, a maioria mencionou possuir entre dois e quatro ${ }^{(11)}$.

Quanto à escolaridade apenas uma apresentava o ensino fundamental completo, as outras referiam o ensino fundamental incompleto. E $m$ relação à renda familiar, as entrevistadas expuseram receber entre um e meio a três salários mínimos por mês, advindo, na maioria das vezes da aposentadoria ou da comercialização de produtos agrícolas oriundos da propriedade (plantação de pessegueiros, derivados do leite, lavoura de milho e feijão), além da criação de animais como porcos, vacas e galinhas.

M uitas das entrevistadas participavam do grupo, desde a sua fundação em 1998, concebida a partir da igreja católica, através da atuação das religiosas, que se deslocavam da cidade de Pelotas até a localidade rural para ministrar palestras às muIheres sobre cuidados em saúde e o uso de plantas medicinais. Diante desta iniciativa, as senhoras prosseguiram os encontros, os quais eram realizados inicialmente nas suas residências e após, no salão da igreja católica local, sede atual do grupo.

Devido algumas participantes do grupo serem vizinhas ou possuírem vínculo familiar, as reuniões passaram a envolver e engajar a cada encontro novas integrantes, valorizando suas habilidades através dos trabal hos manuais (artesanatos) e trocas de ideias quanto ao uso das plantas medicinais na saúde. Este momento terapêutico passou a proporcionar autonomia e troca de saberes, bem como divertimento, tornando-se um espaço social de aprendizagem com relações estáveis e nutritivas, interagindo, confiando, apoiando e também compartilhando informações ${ }^{(12)}$.

Todas as entrevistadas realizavam atividades laborais no seu domicílio. D esta forma, a preparação para a ida ao grupo iniciava-se para algumas delas, no dia anterior, já para outras a rotina demandava em acordar mais cedo, para realizar as atividades como lavar roupas, organizar a casa e/ ou preparar previamente 0 almoço para o marido.

A coordenadora participava há oito anos do M ovimento de M ulheres Camponesas. Ela conduz seu trabal ho de forma voluntária, foi sempre muito bem recebida no grupo, no qual a esperavam com al moço e realizavam rifas durante a tarde objeti- 
vando ar recadar dinheiro para auxiliá-la nos gastos com o transporte, já que a mesma não residia na comunidade onde o grupo ocorria.

No decorrer da coleta de dados, obser vou-se que o grupo organizava-se de forma autônoma, não estando vinculado a nenhum tipo de serviço, seja os de apoio à área rural ou os de saúde.

\section{Autocuidado em saúde realizado pelas agricultoras}

Ao estabelecer um questionamento sobre a compreensão do autocuidado em saúde às mulheres, pode-se perceber que este é um tema que engloba muitas concepções, ligadas especialmente às vivências de cada uma delas.

A utocuidado pra mim éo jeito quea gentese cuida, ése cuidar pra tentar evitar as doenças, não deixar queelas tomem conta ou fiquem grave (M 1).

A utocuidado em saúdeétu fazer um tratamento de saúde preventivo, étu não deixar tu já ter problemas graves pra ti procurar um recurso (M 2).

0 autocuidado exposto pelas entrevistadas está relacionado como uma maneira de evitar o desenvolvimento de doenças, sendo, portanto um cuidado desempenhado pela própria pessoa, com enfoque preventivo. E m consonância, Orem revela em sua teoria sobre o autocuidado, que está ação é uma prática da pessoa para si mesma e desenvolvida por ela mesma, o indivíduo deve ser livre para julgar, utilizando ou rejeitando o que Ihe é oferecido ou ensinado(13).

D entre as atividades de autocuidado realizadas, uma das entrevistadas referiu a realização do exame citopatológico de colo uterino como a efetivação do autocuidado em saúde, já outras informantes mencionaram alguns exames complementares, como a aferição da pressão arterial sistêmica e consulta médica nas unidades básicas de saúde (UBS) rurais.

[ ...] vou sempre no postinho fazer pré câncer e ver a pressão, mesmo assim que eu sinto que ela tá bem, até fiz ano passado, fiz exame de sangue, fiz um eletro, mas graças a D eus tá tudo bem [ ...] (M 3).

[ ...] eu tenho uma médica clínica geral. E la faz meu tratamento específico, éa acupuntura eas plantas, eessas são as minhas coisas [ ...] (M 2).
A maneira com que os profissionais de saúde trabal ham com model o biomédico, não está per mitindo assistir o usuário como um ser integral, e este passa a buscar outras formas de tratamento e promoção da saúde, como as terapias complementares, as quais são abordagens que visam a assistência nas etapas do processo saúde-doença.

D e acordo com o M inistério da Saúde, as principais práticas de terapias complementares são a fitoter apia/ plantas medicinais, acupuntura, crenoter apia e homeopatia ${ }^{(14)}$. D entre estas, a acupuntura e as plantas medicinais foram referidas na prática de autocuidado à saúde pelo grupo de mulheres rurais abordadas no presente estudo.

E stas ações, quando val orizadas pel os profissionais de saúde, permitem resgatar experiências oriundas do saber popular, orientando as mulheres quanto ao cuidado em saúde de forma a torná-las mais autônomas. D esta maneira, se permitirá também resgatar formas de autocuidado, que considerem ações prazer osas em benefício de sua saúde ${ }^{(15)}$. F ato que pode ser percebido a partir das falas a seguir, que revelam a real ização de atividades de artesanato, caminhadas e 0 uso das plantas medicinais como ações de cuidado à saúde.

E u gosto muito detrabal har com artesanato porquepra mim ele é uma terapia, ele levanta a minha autoesti$\mathrm{ma}$, cada coisa que tu faz édiferente etem algo dentro de ti que muda [...] (M 2).

E u tomo chá. Inclusive eu tomo chá tem vários que são tipo calmante, e eu até já acostumei tomar, gosto de tomar chá de noite A té parece que a gente dorme me Ihor também [ ...] a gente atacada dos nervos e coisa assim, aprendi a fazer pintura em tecido, é uma coisa extravasante, eu me sento, pinto, faço um crochezinho, já aprendi fazer, é uma coisa que parece que distrai a gente, acalma [ ...] (M 3).

Deste modo, ao analisar a inserção das plantas medicinais no campo do cuidado, vários são os fatores que contribuem para o maior consumo destas herbáceas, como 0 alto custo dos medicamentos industrializados, o difícil acesso da população à assistência a saúde, além da tendência para a utilização de produtos de origem naturais ${ }^{(16)}$. A o utilizar uma planta medicinal, é necessário saber identificá-la corretamente, conhecer sua composição química e contraindicações, além do emprego de uma dosagem adequada, evitando assim possíveis reações adver sas e/ ou intoxicações. 
A ssim, o uso de plantas medicinais como prática complementar pode contribuir para a saúde dos indivíduos, constituindo-se enquanto parte do sistema de cuidado. N este contexto, nove das entrevistadas relacionaram saúde não apenas ao uso das plantas, mas a uma alimentação adequada, evidenciando tal prática como uma das principais atividades de autocuidado em saúde.

[ ...] eu já me cuidei muito com essa carne já passei pra branca, mas eu como um pouco de carne vermelha, a doutora disse, mas eu sei que é mais verduras e legumes essas coisas que ajudam na saúde né [ ...] (M 4).

T emos que saber viver para manter nossa saúde e alimentação também, alimentação em primeiro lugar. U ma alimentação errada nos deixa toda errada também. N ossa alimentação em casa é muito correta. A gente procura comer carne branca também, claro que a gente faz a ver melha, mas cuidar muito da alimentação cuidar da carne, horta, gordura, evitar gordura e todas essas coisas (M 5).

A alimentação e a nutrição constituem-se como requisitos básicos para a realização do cuidado e a proteção da saúde. As práticas alimentares saudáveis, como a redução de gordura ingerida e o consumo de frutas e verduras, citadas pelas entrevistadas, servem como medida preventiva para reduzir os riscos de diversas doenças ${ }^{(17)}$. A alimentação faz parte dos valores essências dos moradores da área rural, pensamento que transcende a refeição da família e a promoção de saúde, mas que também representa a produção resultante do trabalho por eles executado ${ }^{(18)}$.

F rente aos cuidados com a alimentação, convém ressaltar ainda o plantio de alimentos com redução e/ ou isenção de agrotóxicos e o pouco uso de condimentos industrializados no preparo das refeições, ações estas, idealizadas pelas entrevistadas e evidenciadas abaixo:

E u cuido muito assim com a comida que a gente faz, pra gente usar os temperos mais naturais, e plantar assim botar pouco defensivos e essas coisas assim, pra gente ter uma saúde mel hor (M 1).

É uma coisa que também eu acho, que pra mim é a alimentação né, a gente procura usar bastante tudo aquilo quea gente sabe que não tem muito agrotóxico, eu já tenho minha horta, planto as coisas ali, pra saber o que a gente come [...] (M 3).
0 autocuidado incide na prevenção de riscos à saúde, e os ag rotóxicos, quando utilizados de for ma indiscriminada podem provocar intoxicações, além de estarem relacionados à ocorrência de abortamentos e várias doenças.

0 autocuidado das mulheres rurais também abrange o contexto familiar, a social ização de crenças e hábitos através das gerações e é evidenciada nas falas das entrevistadas, que afirmam utilizar os mesmos métodos de cuidado aprendidos com a sua família.

A h, tudo o que eu acho bom pra mim, pra eles também. E u passo pras minhas filhas, passo pro meu filho, pros meus netos. É, a gente deve se alimentar assim, comer essas coisa que são natural ou que a gente sabe que fazem bem pra saúde $\mathrm{E}$ a mesma coisa, negócio com chá (M 3).

Ol ha, eles tem mais ou menos os mesmos costumes, os cuidados que eu tenho, eles procuram manter al guma coisa, claro que ninguém é igual, ninguém faz igual ninguém pensa igual, mas eles procuram caminhar mais ou menos na linha (M 2).

É importante destacar que para cuidar de famílias rurais, faz-se necessário que se conheça seu espaço, sua estrutura, sua dinâmica, ou seja, suas particularidades como cultura, crenças, religião, etnias e hábitos de saúde que estão presentes na família. É necessário compreender este conjunto de valores, os quais diferem de um grupo para outro ${ }^{(19)}$.

As ações de autocuidado são resultantes de um complexo processo de atenção à saúde, que envolve o fortalecimento das capacidades individuais e coletivas dos indivíduos, atuando sobre múltiplas dimensões. De um lado intervenções de âmbito profissional e de outro a singularidade e autonomia dos sujeitos sobre o ambiente social e ecológico em que se constituem ${ }^{(20)}$

\section{Papel dos profissionais no autocuidado em saúde}

Quanto à participação dos profissionais de saúde na orientação do autocuidado, houve divergências das entrevistadas no que diz respeito a atuação dos agentes comunitários de saúde (ACS) e do enfermeiro, pois algumas afirmaram que eles interferem de maneira positiva e outras que não há uma participação efetiva dos mesmos. D iante desta realidade, foi constatado que o grupo de mulhe- 
res abordadas se fortalece mediante a condução de suas atividades mensais, enriquecendo os seus saberes para uma atuação mais segura no processo saúdedoença. $F$ ato evidenciado nas fal as que seguem:

A qui no postinho tem as agentes de saúde que passam em casa eaí ensi nam alguma coisa, mas a genteaprende muito aqui no grupo, troca as experiências eas doenças e como se cuidar e qual chá eu tomo pra cada coisa esefunciona, mas o pessoal do posto também, mas a gente não tem tempo deir lá e perguntar então aprende mais aqui mesmo (M 1).

Eles [ ACS] ajudam muito porque tem muitas pessoas, principalmente aqui na colônia, nem sabem o queé, como se cuidar, como fazer né, então as gurias mesmo que trabalham, que visitam nas casas, elas conversam bastante e, até usam assim um linguajar mais simples pras pessoa entender (M 3).

T em um agente de saúde que aparece a cada três, quatro meses lá em casa, mas não interfere em nada (M 2).

O estímulo para a realização do autocuidado é importante. Os profissionais de saúde, através das ações educativas devem buscar a participação e 0 questionamento das mulheres sobre os diferentes aspectos relacionados à prevenção, à educação, às doenças e às ações de controle, buscando sensibilizar estas para a adoção de atitudes e comportamentos compatíveis ou condizentes com uma vida saudável(21).

0 enfermeiro precisa mobilizar no cliente a busca de novos conhecimentos e aprendizagens para a prática do autocuidado e o enfrentamento das situações diárias. A ções que possibilitam a diminuição da dependência dos usuários nos serviços de saúde, assim como, o planejamento da assistência a partir das necessidades e preferências do indivíduo, e não do profissional(14).

Deste modo, muitas são as formas de autocuidado provenientes deste amplo espaço coletivo que é o meio rural. Assim, cabe aos profissionais de saúde estar cientes de que o cuidado envolve o ser como um todo, sendo necessário inserir-se neste contexto diferenciado e inerente a zona rural, buscando qualificar e humanizar 0 atendimento prestado.

\section{CONSIDERAÇÕES FINAIS}

A realização deste trabal ho oportunizou conhecer as ações de autocuidado de um grupo de mulheres rurais do município de Pelotas. Diante da riqueza de saberes manifestados pel as infor mantes, acredita-se que cada uma poderia originar um trabal ho a ser realizado, devido a amplitude das suas vivências e experiências no cuidado em saúde.

As percepções encontradas do processo saúdedoença evidenciaram a importância que as agricultoras atribuem à saúde, o que está diretamente correlacionado ao interesse pelo conhecimento e compartilhamento das formas de cuidado para com a saúde no meio rural.

Pode-se perceber uma mudança na realidade rural, diante do acesso às informações e aos recursos oriundos no meio urbano, tornando as agricultoras cada vez mais atuantes, unidas e organizadas, seja na busca por seus direitos ou pel o seu bemestar, pela sua saúde. A ssim ressalta-se a importância da execução de outros trabal hos com estas mulheres e os profissionais de saúde que atuam nesta área, para compreender a visão destes e identificar mecanismos que possam reforçar o vínculo das usuárias com a UBS, qualificando assim, a promoção da saúde e, por consequência, o autocuidado entre as agricultoras rurais.

A compreensão do enfermeiro frente ao autocuidado precisa considerar as diversas maneiras de buscar saúde, de acordo com o contexto apresentado, para assim prestar um cuidado integral que val orize o ser humano nas suas especificidades.

\section{REFERÊ NCIAS}

1 Guilhoto JJM, Ichihara SM, Silveira SV, Diniz BPC, Azzoni CR, M oreira GRC. A importância da agricultura familiar no Brasil eem seus $\mathrm{E}$ stados. In: 350 A nais do Encontro Nacional de E conomia; 2007 dez 4-7; Recife, Brasil [ Internet] . Recife: AN PE C; 2007 [ citado 2010 jan 18] . Disponível em: http:// www.anpec. org.br/ encontro2007/ artigos/ A 07A 089.pdf.

2 Instituto Brasileiro de G eografia e Estatística. Censo 2010. Rio de Janeiro; 2010 [ citado 2011 maio 01] . D isponível em: http:/ / www.ibge.gov.br/home/ esta tistica/ populacao/ cens02010/ primeiros_resultados/ populacao_por_municipio.shtm.

3 Brumer A. G ênero e agricultura: a situação da muIher na ag ricultura do Rio G rande do Sul. Estud Fem. 2004;12(1):205-27.

4 M inistério da Saúde (BR), Secretaria de Vigilância em Saúde, Secretaria de A tenção à Saúde. D iretrizes e recomendações para o cuidado integral de doenças 
crônicas não-transmissíveis: promoção da saúde, vigilância, prevenção e assistência. Brasília (DF); 2008.

5 M inistério da Saúde (D F ). Política N acional de A tenção Integral à Saúde da M ulher: plano de ação 20042007. Brasília (DF); 2004.

6 M inistério da Saúde (BR), Secretaria de Vigilância em Saúde, Secretaria de A tenção à Saúde. Política N acional de Promoção da Saúde. Brasília (DF ); 2006.

7 Santos I, Sarat CN F. M odalidades de aplicação da teoria do autocuidado de 0 rem em comunicações científicas de enfermagem brasileira. Rev Enferm UERJ. 2008;16(3):313-8.

8 M inayo M CS. 0 desafio do conhecimento: pesquisa qualitativa em saúde. 11aㅡ ed. São Paulo: HucitecAbrasco; 2008.

9 M inistério da Saúde (BR ), Consel ho N acional de Saúde. Resolução 196, de 10 de outubro de 1996: diretrizes enor mas regulamentador as de pesquisa envolvendo seres humanos. Brasília (DF ); 1996.

10 Bardin L. A nálise de conteúdo. Lisboa: E dições 70; 2000.

11 T hum M A. Saberes relacionados ao autocuidado em saúde entre mulheres da área rural do município de Pelotas [ monografia] . Pel otas: F acul dade de E nfermagem, U niversidade F ederal de Pelotas; 2010.

12 M eneghel SN, Camargo M , Fasolo LR, M attiello DA, Silva RCR, Santos T CB, et al. M ulheres cuidando de mulheres: um estudo sobre a Casa de A poio Viva M aria, Porto A legre, Rio G rande do Sul, Brasil. Cad Saúde Pública. 2000;16(3):747-57.

13 Foster PC, Janssens N P, D orothea E. Orem. In: George JB. T eorias de Enfermagem: os fundamen- tos para a prática profissional. Porto Alegre: Artes M édicas; 1993. p. 90-107.

14 M inistério da Saúde (BR), Secretaria de A tenção à Saúde, D epartamento deA tenção Básica. Política N acional de Práticas Integrativas e Complementares no SU S - PN PIC-SU S. Brasília (DF); 2006.

15 M eneghel SN, Barbiani R, Steffen $H$, W under AP, Roza M D, Rotermund J, et al. I mpacto de grupos de mulheres em situação de vulnerabilidade de gênero. Cad Saúde Pública. 2003;19(4):955-63.

16 Simões $C M$, M entz LA, Schemkel E P, I rgang BE, Stehmann JR. Plantas da medicina popular no Rio Grande do Sul. 5a ed. Porto A legre: E d. U niversidade/ UFRGS; 1998.

17 M inistério da Saúde (BR), Secretaria de A tenção à Saúde, D epartamento de A tenção Básica. Política $\mathrm{Na-}$ cional de Alimentação e Nutrição. Brasília (DF); 2003.

18 Denardin Budó M L, Gonzales RM B, Beck CLC. Saúde e trabalho: uma correlação de conceitos na perspectiva de uma população rural e de Christophe Dejours. Rev G aúcha Enferm. 2003;24(1):4352.

19 Zillmer JGV, Schwartz E, Ceolin T, Heck RM. The present-day rural family: a challenge for nursing. Rev Enferm UFPE. 2009;3(3):319-24.

20 Santos L M , Ros M A, Crepaldi M A, Ramos LR. G rupos de promoção à saúde no desenvolvimento da autonomia, condições de vida e saúde. Rev Saúde Pública. 2006;40(2);346-52.

21 T hum M , H eck R M , Soares M C, D eprá AS. Câncer de colo uterino: percepção das mulheres sobre prevenção. Ciênc Cuid Saúde. 2008;7(4):509-16.

\section{Endereço da autora / Dirección del autor / Author's address:}

Teila Ceolin

U niversidade F ederal de Pelotas

$F$ acul dade de E nfer magem

Rua G omes Carneiro, 01, Porto

96010-610, Pelotas, RS

E-mail:teila.ceolin@ig.com.br
Recebido em: 04/ 01/ 2011

A provado em: 30/ 05/ 2011 